\title{
NOCCAEA PERFOLIATA OR MICROTHLASPI PERFOLIATUM (BRASSICACEAE), NEW TO THE FLORA OF TEXAS, U.S.A.
}

\author{
Amanda K. Neill \\ Botanist-at-large \\ Krum, Texas 76249, U.S.A. \\ amanda.neill@gmail.com
}

\author{
Sam R. Kieschnick \\ DFW Urban Biologist \\ Cedar Hill State Park, 1570 FM1382 \\ Cedar Hill, Texas 75104, U.S.A. \\ sam.kieschnick@tpwd.texas.gov
}

\begin{abstract}
The non-native plant species contentiously known as either Noccaea perfoliata or Microthlaspi perfoliatum is reported in Texas for the first time, with iNaturalist observations from Collin, Dallas, and Grayson counties.

\section{RESUMEN}

Se reporta por primera vez para Texas con observaciones de iNaturalist de los condados de Collin, Dallas y Grayson, la especie de planta no-nativa conocida polémicamente como Noccaea perfoliata o Microthlaspi perfoliatum
\end{abstract}

Key Words: Noccaea, Microthlaspi, Coluteocarpeae, Brassicaceae, pennycress, adventive, non-native, state record, Texas; iNaturalist

\section{INTRODUCTION}

The diminutive, herbaceous early-spring annual commonly known as claspleaf pennycress, perfoliate pennycress, or thoroughwort pennycress (Brassicaceae: Coluteocarpeae) is native to Europe, eastern Asia, and northern Africa (Al-Shehbaz 2010). Britton \& Brown (1913) noted the plant's early introduction to the western hemisphere in New York and Ontario; it is now a naturalized weed of roadsides and disturbed areas across a midsection of the eastern and central U.S., mainly from southern New England to the central Great Plains, with a few records from Washington and Idaho (iDigBio.org). The species has been recognized since the time of Linnaeus and is unquestionably distinct, but its generic placement has been tumultuous, resulting in confounding disagreement amongst currently authoritative nomenclatural resources. This creates a difficulty in crafting the appropriate announcement of its presence in the Texas flora, and compels us to discuss the nomenclatural history of the taxon prior to the details of its discovery in the state.

\section{NOMENCLATURAL DISCUSSION}

The species of note was long included in the large and unruly genus Thlaspi (as T. perfoliatum L.) in North American accounts (Payson 1926; Holmgren 1971; Rollins 1993). Based on morphological characters, Meyer $(1973,1979,2003)$ split Thlaspi into 12 genera, using the species in question to typify the new genus Microthlaspi (as M. perfoliatum (L.) F.K. Mey.), while also resurrecting the genus Noccaea Moench. The next two decades produced a veritable spate of molecular phylogenetic studies (well-summarized by Koch and Mummenhoff (2001) and Koch and Al-Shehbaz (2004)) that asserted the unnaturalness of Thlaspi sensu lato and supported many of Meyer's segregate generic concepts (including Noccaea), but brought into question the monophyly of Microthlaspi. In the Flora of North America (Al-Shehbaz 2010), this species was treated as the only representative of Microthlaspi, promulgating a position still held by some respected taxonomic resources (e.g., Brassibase (Koch et al. 2020)). However, Al-Shehbaz's generic synopsis of Noccaea (2014) subsumed Microthlaspi and nine other Meyer-segregate genera and published the new combination Noccaea perfoliata (L.) Al-Shehbaz, a name now accepted by other authoritative resources (e.g., The Global Biodiversity Information Facility's GBIF.org and Kew's PlantsoftheWorldOnline.org). Recent tribal-scale phylogenetic studies have taken contrary (Ali et al. 2016) or equivocal (Özüdoğru et al. 2019) positions, with the latter calling for more comprehensive 
analyses, stating, "Although we lean, at least for now, toward supporting the position of Al-Shehbaz (2014) in accepting a broad concept for Noccaea, we believe that it may not be the final answer."

For the purposes of this state record publication, we assert Noccaea perfoliata (L.) Al-Shehbaz is the correct name for this entity, following Al-Shehbaz (2014); however, as that name has not yet been consistently adopted across authoritative platforms, we retain the synonym Microthlaspi perfoliatum (L.) F.K. Mey. in our title, hoping to provide a fair chance to every reader and indexing service for discovery and recognition.

\section{DOCUMENTATION IN TEXAS}

Claspleaf pennycress - under any of its scientific names-is absent from checklists and floras of Texas (Correll \& Johnston 1970; Hatch et al. 1990; Jones et al. 1997; Diggs et al. 1999; Turner et al. 2003) and checklists of non-native plant species in Texas (Nesom 2009; Aplaca 2010). Texas was not included in the range in Al-Shehbaz's FNA treatment (2010) or the most recent multistate regional flora for the southeastern U.S. (Weakley 2020). Other than reproduction of the recent iNaturalist observation records we cite below in detail, the species has not been mapped as occurring in Texas by any authoritative species-mapping resource or herbarium portal, such as the PLANTS Database (USDA-NRCS 2021), BONAP.net (Kartesz 2015), iDigBio.org, Bison.USGS.gov, Explorer.Natureserve.org, EDDMaps.org, or PlantsoftheWorldOnline.org. The species has been recorded infrequently in the neighboring states of Oklahoma, Arkansas, and Louisiana (Kartesz 2015; and according to digitized herbarium records in the TORCH and SERNEC herbarium portals), but these reported localities were not near the Texas border.

The recent appearance of claspleaf pennycress in Texas came to the attention of the first author (A.K.N.) while searching for uncommon taxon records on iNaturalist.org during Brassicaceae treatment research for the Illustrated Flora of East Texas, Vol II, in preparation by the Botanical Research Institute of Texas (BRIT) Press. iNaturalist is an immensely popular and well-curated global citizen-science biodiversity observation tool, with over 1.3 million users and more than 50 million documented observations of wild organisms (California Academy of Sciences 2020). Accessible online at iNaturalist.org or via a free stand-alone app, contribution is open to any registered user following the guidelines. Contributors document a record of organism occurrence by providing all the data one would typically expect to find on a natural history collection label, supported by one or more photographs of the organism in situ. Annotations are facilitated and encouraged; annotations in agreement can accrue to result in designation of a record's quality as "research-grade," and these records are shared with the Global Biodiversity Information Facility (GBIF.org). Skilled amateur and professional biologists have enriched iNaturalist with high-quality observations including precise geolocalities and high-resolution photographs, and while these lack the physical permanence of a museum-deposited voucher, they can be linked to records of such, if a sample of the organism is simultaneously obtained. Most importantly, the born-digital observation can be immediately uploaded for research use, while a physical voucher may take weeks or years to be processed, accessioned, and digitized for remote examination.

In the pandemic years of 2020-2021, every digital observation and specimen gained additional value, allowing timely research to continue, remote from the restrictions and risks of the physical world. As former staff of BRIT-SMU-VDB, one of the larger herbaria in the United States, we are compelled to affirm that the responsible collection of physical vouchers will forever remain integral to the growth and value of natural history collections and should be highly encouraged-when legality, conservation status, and population size allow it. However, many unusual records would have been long-delayed in recognition and collection (e.g., Singhurst et al. 2020) if the traditional methods of documentation were the only acceptable methods. Urban species records in particular may be passed over by professional biologists, but these are being documented more frequently by citizen scientists— by an order of magnitude, for some charismatic organisms (Spear et al. 2017).

Claspleaf pennycress was apparently first observed in Texas on 31 Jan 2019 by the second author (S.R.K., who also identified the species; Figs. 1-2), in the north-central part of the state in Grayson Co.; this occurrence was documented with precise geocoordinates and several high-resolution images in iNaturalist, where 

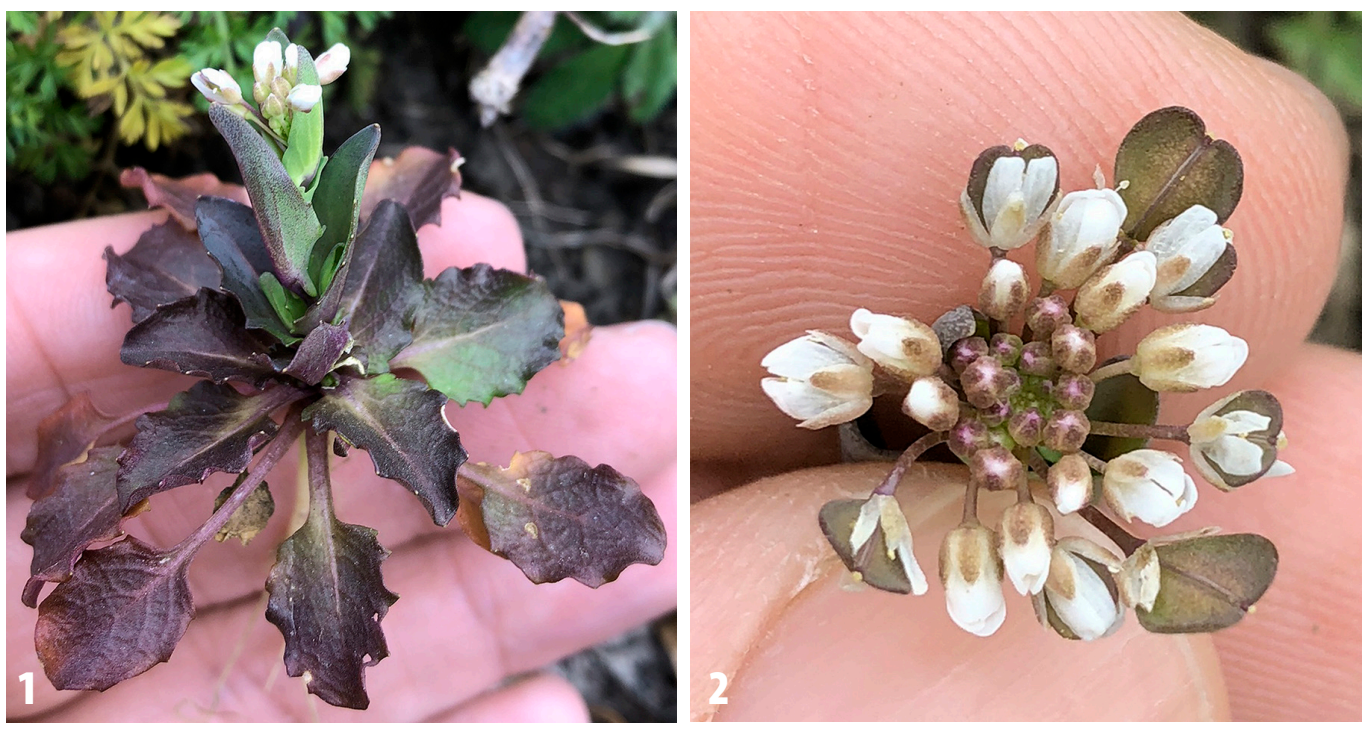

FiGs. 1-2. Claspleaf pennycress in Grayson Co., Texas, on 2019-01-31: 1. petiolate rosette leaves and early inflorescence (photo by Sam Kieschnick; iNaturalist obs. 20000793). 2. inflorescence with immature fruits (photo by Sam Kieschnick; iNaturalist obs. 20000793).

observations are assigned a unique number that forms the last segment of the permanent URL, i.e., S.R.K.'s Grayson Co. observation is \#20000793 and can be viewed at: https://www.inaturalist.org/observations/20000793. A second locality was documented by S.R.K. on 4 Mar 2020 in Collin Co. (iNaturalist observation 39559646) (Figs. 3-5). A third observation was made by iNaturalist contributor Annika Lindqvist on 7 Mar 2020 in Dallas Co. (iNaturalist observation 39684417). The excellent quality and resolution of the images of entire plants, racemes, flowers, and maturing fruit on iNaturalist supporting these well-documented observations were sufficient for definitive determination as the fortunately morphologically-distinctive Noccaea perfoliata (= Microthlaspi perfoliatum); Dr. Ihsan A. Al-Shehbaz at MO viewed these records and provided his expert confirmation (pers. comm. to A.K.N.).

These observations hinted at the incipient naturalization of an adventive, exotic species in our state, providing the impetus to initially submit this note based on observations alone, unconfident in our ability to obtain reproductive vouchers of this ephemeral spring annual between the continuing COVID pandemic and the enthusiastic mowing schedules apparent at two of the localities. Thankfully, we were able to return to the Collin Co. location in Mar 2021 and obtain a set of specimens for distribution by BRIT-SMU-VDB.

Herbarium voucher: U.S.A. TeXAs. Collin Co.: Lavon, Mallard Park, W of TX-78, S of park/lake access road, just E of path to rest area, $33.048415^{\circ},-96.425459^{\circ}$, accuracy $2 \mathrm{~m}$, large population in flower and fruit, on regularly mown roadbank, in full sun, on sandy soil; with Sherardia arvensis, Medicago, Oxalis, 12 Mar 2021, S.R. Kieschnick \& A.K. Neill 1751 (BRIT); Sam Kieschnick (sambiology) iNaturalist obs. 71085243 (https://www.inaturalist.org/observations/71085243).

Digital vouchers [additional locality and habitat data interpreted by A.K.N. inserted in brackets]: U.S.A. Texas. Collin Co.: Lavon [Mallard Park], 33.048415,$-96.425459^{\circ}$, accuracy 6 m, [with Medicago, Trifolium, Anemone, Veronica], 4 Mar 2020, S.R. Kieschnick (sambiology) iNaturalist obs. 39559646 (https://www.inaturalist.org/observations/39559646). Lavon [Mallard Park], 33.048415 ${ }^{\circ},-96.425459^{\circ}$, accuracy 6 m, 5 Mar 2021, A.K. Neill (aneill) iNaturalist obs. 71287992 (https://www.inaturalist.org/observations/71287992). Dallas Co.: Ferris [Parkinson Rd., S of Tenmile Creek], 32.563171 ${ }^{\circ},-96.62362^{\circ}$, accuracy 6 m, 7 Mar 2020, Annika Lindqvist (annikaml) iNaturalist obs. 39684417 (https:// www.inaturalist.org/observations/39684417). Grayson Co.: Howe [Bicentennial Park, W of I-75, just S of southern baseball diamond], $33.51114^{\circ},-96.618564^{\circ}$, accuracy $4 \mathrm{~m}$, [on regularly mown field, in full sun, at top of slope to adjacent creek drainage; with Sherardia arvensis, Soliva, other spring weeds], 31 Jan 2019, S.R. Kieschnick (sambiology) iNaturalist obs. 20000793 (https://www.inaturalist.org/ observations/20000793). 

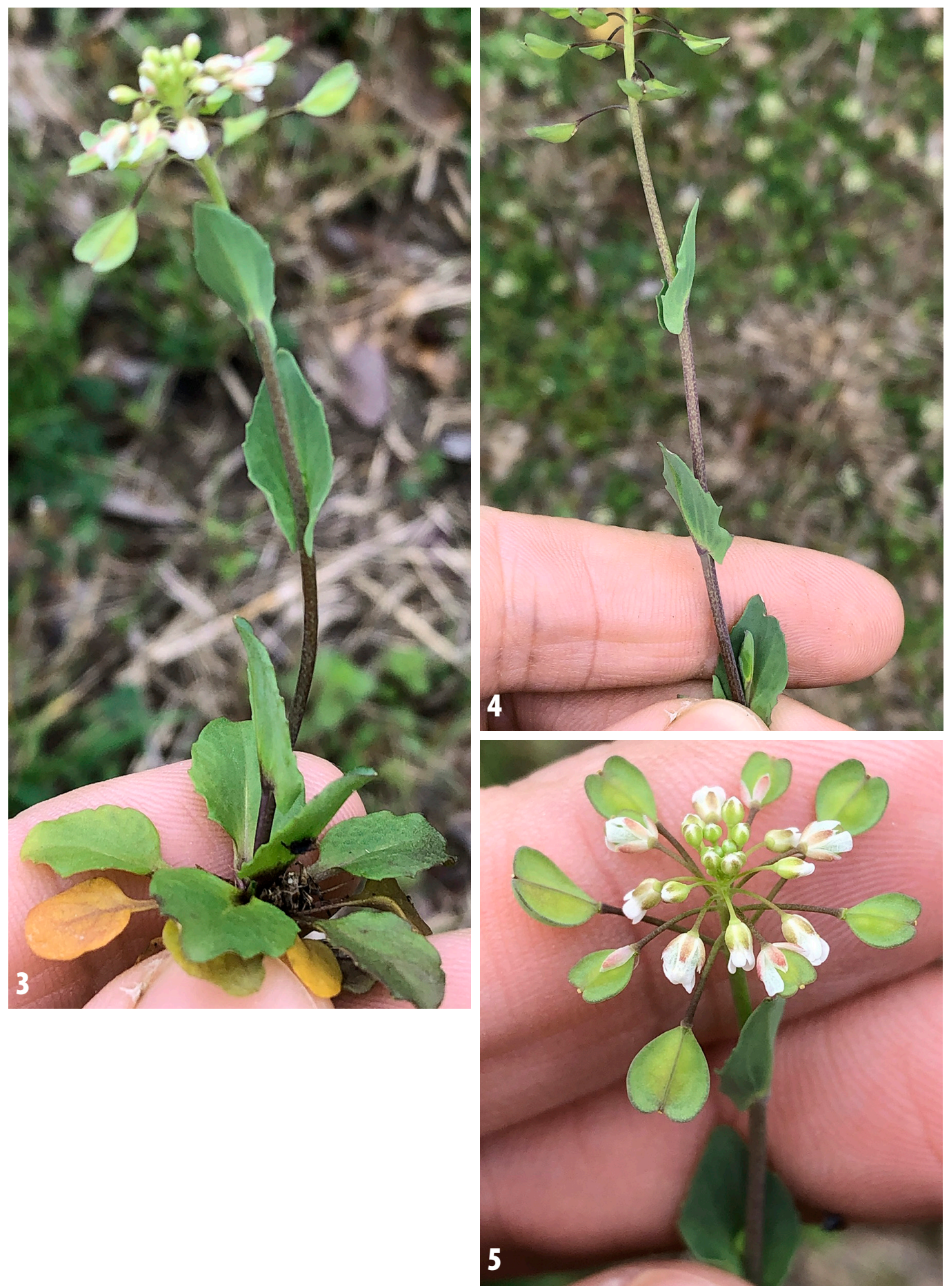

Fics. 3-5. Claspleaf pennycress in Collin Co., Texas, on 2020-03-04: 3. petiolate basal leaves and cordate-clasping (amplexicaul) stem leaves (photo by Sam Kieschnick; iNaturalist obs. 39559646); 4. cordate-clasping stem leaves and lower raceme with maturing fruits (photo by Sam Kieschnick; iNaturalist obs. 39559646); 5 . inflorescence with immature fruits (photo by Sam Kieschnick; iNaturalist obs. 39559646). 
We encourage other botanists in the state, particularly in northeast Texas, to be alert for this species, and to document any additional populations with herbarium vouchers and concurrent iNaturalist observations. Herbarium searches may uncover other records in the state. Specimens might be misidentified as Capsella bursa-pastoris (L.) Medik. or Thlaspi arvense L., due to similarities in winter-annual habit, clasping-auriculate stem leaves, flattened obcordate silicles with winged margins, and white corollas less than $5 \mathrm{~mm}$ long. Capsella bursa-pastoris is stellate-pubescent, with basal leaves pinnately lobed or runcinate, and cuneate fruit bases, whereas N. perfoliata is nearly glabrous, with basal leaves obtusely dentate or entire, and obtuse fruit bases. Thlaspi arvense fruits are held \pm vertically, and have wide marginal wings (3.5-5 mm wide near apex) and a narrow, deep apical notch (to $5 \mathrm{~mm}$ deep), and the seed coats are concentrically striate, but $N$. perfoliata fruits are held more horizontally, and have narrower wings (1-2 mm wide near apex) and a wider, shallower apical notch (1-1.5 mm deep), and the seed coats are smooth. Noccaea perfoliata also tends to be half the size of either of those species, with stems typically less than $40 \mathrm{~cm}$ tall. A description follows, based on Al-Shehbaz (2010).

Description._Noccaea perfoliata (L.) Al-Shehbaz (= Microthlaspi perfoliatum (L.) F.K. Mey.) (Figs. 1-5). Plants diminutive, herbaceous, winter annuals; glabrous and glaucous; stems to $28(-40) \mathrm{cm}$, often purpletinged, sometimes branching; basal leaves in a loose rosette (some withered by fruiting), petiolate, blades elliptic to ovate, to $2(-2.7) \mathrm{cm}$ long, apex rounded, margins entire or remotely and obtusely dentate; stem leaves alternate, sessile, ovate-cordate, to $4(-5.5) \mathrm{cm}$ long, margins entire to repand or with a few obtuse teeth, bases auricled and strongly cordate-clasping (amplexicaul); racemes corymbose, several-flowered, considerably elongated in fruit; sepals 4, green with white margins, apices often pinkish or purplish; petals 4, white, 2-3.5(-4.7) mm long $\times 0.5-1.3 \mathrm{~mm}$ wide, spatulate to oblanceolate, claw obscure; stamens 6 , slightly tetradynamous; fruiting pedicels slender, $2.5-8 \mathrm{~mm}$ long, spreading or horizontal; fruits silicles, dehiscent, sessile (lacking a gynophore), obcordate, 3-6.5(-8) mm long $\times(2.5-) 3-6(-7) \mathrm{mm}$ wide, strongly flattened perpendicular to the replum separating the two locules, the midline (valve) keeled, marginal wings narrow basally increasing to 1-2 mm wide near fruit apex, apical notch 1-1.5 mm deep; style obsolete or to $0.3 \mathrm{~mm}$ long, stigma capitate; ovules 4-8 per ovary; seeds ovoid, smooth, yellowish, unwinged, mucilaginous when wetted. Flowering Jan-Mar (in Texas).

\section{CONCLUSION}

The documentation of an adventive, annual, exotic weed in Texas seems an inconsequential thing amid the existential turmoil of the COVID-19 pandemic, and it feels strange to focus on the communication of this minor botanical drama. This little plant is not generally considered noxious in North America, and is unlikely to have major economic impacts if it should naturalize in Texas; it merely joins the huge cohort of other European springtime annuals and biennials that thrive on disturbed ground and grassy, weedy roadsidesspecies that infrequently displace or crowd out any native plants in those already completely unnatural environments. As we consider the ease of weed propagule dispersal, we are now witnesses to the worldwide dispersal of the most noxious organism of our lifetimes. While the documentation of the SARS-CoV2 invasion is appropriately prolific, the record of it should be immortalized in all our rhetoric, perhaps especially in the typically dispassionate documentation of natural history-perhaps the only news we will still re-read, hundreds of years after it is written.

\section{ACKNOWLEDGMENTS}

We sincerely thank Ihsan A. Al-Shehbaz for confirming the species determination and reviewing a draft of this manuscript, and for his heroic research untangling the mysteries of the mustard family. We are grateful for the organizations and funding sources that support iNaturalist.org, and thank all the citizen scientists contributing valuable observations of Texas plants. We appreciate helpful manuscript reviews from Jason Singhurst and David Lemke. Finally, we can hardly express our gratitude to all those who labored collaboratively for decades to create the standards, tools, and portals that now allow us to reap the benefits of digitized natural history collections and associated literature. We thank Texas Parks and Wildlife for publication support. 


\section{REFERENCES}

Al-Shehbaz, I.A. 2010. Microthlaspi. In: Flora of North America Editorial Committee, eds. Fl. North Amer. 7:599-600. Oxford Univ. Press, New York and Oxford. http://www.efloras.org/florataxon.aspx?flora_id=1\&taxon_id=314393

Al-Shehbaz, I.A. 2014. A synopsis of the genus Noccaea (Coluteocarpeae, Brassicaceae). Harvard Pap. Bot. 19(1):25-51. https://huh.harvard.edu/files/herbaria/files/19_1_25_al-shehbaz.pdf

Ali, T., A. Schmuker, F. Runge, I. Solovyeva, L. Nigrelli, J. Paule, A.K. Buch, X. XiA, S. Ploch, O. Orren, \& V. Kummer. 2016. Morphology, phylogeny, and taxonomy of Microthlaspi (Brassicaceae: Coluteocarpeae) and related genera. Taxon 65(1):79-98. doi:10.12705/651.6

ApLACA, J. 2010. The non-native flora of Texas. Thesis, Dept. of Biology, Texas State Univ., San Marcos. https://digital. library.txstate.edu/handle/10877/3149

Britton, N.L. \& A. Brown. 1913. An illustrated flora of the northern United States: Canada and the British Possessions from Newfoundland to the parallel of the southern boundary of Virginia, and from the Atlantic Ocean westward to the 102nd meridian, 2nd Ed. (Vol. 2). Charles Scribner's Sons, New York, U.S.A.

California Academy of Sciences. 2020. Global nature observation network iNaturalist surpasses 50 million wild plant and animal observations. https://www.calacademy.org/press/releases/inaturalist-50-million

CorRelL, D.S. \& M.C. Johnston. 1970. Manual of the vascular plants of Texas. Texas Research Foundation, Renner, Texas, U.S.A.

DigGs, G.M., B.L. LIPSCOMB, \& R.J. O'Kennon. 1999. Shinners \& Mahler's illustrated flora of North Central Texas. Sida Bot. Misc. 16. Botanical Research Institute of Texas Press, Fort Worth, Texas, U.S.A.

Hatch, S.L., K.N. Gandhi, \& L.E. Brown. 1990. Checklist of the vascular plants of Texas. Texas Agric. Exp. Sta. Misc. Publ. 1655:1-158.

Holmgren, P.K. 1971. A biosystematic study of North American Thlaspi montanum and its allies. Mem. New York Bot. Gard. 21:1-106.

INAtUralist.org. 2021. The California Academy of Sciences. http://www.inaturalist.org/. Accessed Mar 2021.

JonEs, S.D., J.K. WIPFF, \& P.M. Montgomery. 1997. Vascular plants of Texas: A comprehensive checklist including synonymy, bibliography, and index. Univ. of Texas Press, Austin, U.S.A.

KARTESZ, J.T. 2015. The Biota of North America Program (BONAP) Taxonomic Data Center. Chapel Hill, N.C. [Maps generated from Kartesz, J.T. 2015-onward. Floristic Synthesis of North America, Biota of North America Program (BONAP)]. http://www.bonap.net/tdc. Accessed Mar 2021.

$\mathrm{Koch}$, M. \& I.A. Al-Shehbaz. 2004. Taxonomic and phylogenetic evaluation of the American "Thlaspi" species: Identity and relationship to the Eurasian genus Noccaea (Brassicaceae). Syst. Bot. 29(2):375-384. doi: 10.1600/036364404774195566

Koch, M. \& K. Mummenhoff. 2001. Thlaspi s. str. (Brassicaceae) versus Thlaspi s. I.: morphological and taxonomical characters in the light of ITS nrDNA sequence data. PI. Syst. Evol. 227:209-225. doi: 10.1007/s006060170049

Koch, M.A., M. Kiefer, D.A. German, I.A. Al-Shehbaz, A. Franzke, K. Mummenhoff, \& R. Schmickl. 2020. BrassiBase: Tools and biological resources for Brassicaceae character and trait studies—version 1.3. University of Heidelberg, Germany. http:// brassibase.cos.uni-heidelberg.de/. Accessed Mar 2021.

MeYer, F.K. 1973. Conspectus der "Thlaspi"-Arten Europas, Afrikas und Vorderasiens. Feddes Repert. 84:449-470. doi: 10.1002/fedr.19730840503

MeYER, F.K. 1979. Kritische revision der "Thlaspi"—Arten Europas, Afrikas und Vorderasiens, I. Geschichte, Morphologie und Chorologie. Feddes Repert. 90:129-154. doi: 10.1002/fedr.19790900302

MEYER, F.K. 2003. Kritische revision der"Thlaspi"_Arten Europas, Afrikas und Vorderasiens, Spezieller Teil, III. Microthlaspi FK Mey. Haussknechtia 9:3-59. https://www.zobodat.at/pdf/Haussknechtia_9_2003_0003-0059.pdf

Nesom, G.L. 2009. Assessment of invasiveness and ecological impact in non-native plants of Texas. J. Bot. Res. Inst. Texas 3(2):971-991. https://www.jstor.org/stable/41971892

ÖzüdoĞru, B., K. Özgışı, B. Tarikahya-Hacioğlu, A. Ocak, K. Mummenhoff, \& I.A. Al-Shehbaz. 2019. Phylogeny of the genus Noccaea (Brassicaceae) and a critical review of its generic circumscription. Ann. Missouri Bot. Gard. 104(3):339-354. doi: $10.3417 / 2019347$

Payson, E.B. 1926. The genus Thlaspi in North America. Univ. Wyoming Publ. Sci., Bot. 1:145-163.

Roluins, R.C. 1993. The Cruciferae of continental North America: systematics of the mustard family from the Arctic to Panama. Stanford University Press, Stanford, California, U.S.A. 
SinghuRSt, J.R., J.N. Mink, \& W.C. Holmes. 2020. Eulophia graminea (Orchidaceae) naturalized in Texas. Phytoneuron 202022:1-5. http://www.phytoneuron.net/2020Phytoneuron/22PhytoN-Eulophiagraminea.pdf

SPEAR, D.M., G.B. PAuLY, \& K. Kalser. 2017. Citizen science as a tool for augmenting museum collection data from urban areas. Frontiers Ecol. Evol. 5:86. https://www.frontiersin.org/articles/10.3389/fevo.2017.00086/full

Turner, B.L., H. Nichols, G. Denny, \& O. Doron. 2003. Atlas of the vascular plants of Texas, Vol. 1: Dicots. Sida Bot. Misc. 24. Botanical Research Institute of Texas Press, Fort Worth, Texas, U.S.A.

USDA NRCS. 2021. The PLANTS Database. National Plant Data Team, Greensboro, North Carolina, U.S.A. https://plants. sc.egov.usda.gov/. Accessed Mar 2021.

WEAKLEY, A.S. 2020. Flora of the southeastern United States. Univ. North Carolina, Chapel Hill, U.S.A. October 2020 edition available at https://ncbg.unc.edu/research/unc-herbarium/flora-request/ 